\title{
Design and Development of Effective braking system for Pneumatic Tyer Bullock Carts
}

\author{
Yogesh S. Patil ${ }^{1}$, Ganesh H. Kawade ${ }^{2}$ \\ ${ }^{I}$ (Asst. Professor, Department of Automobile Engineering, R. I. T. Sakharale, Maharashtra, India) \\ ${ }_{2}^{2}$ (Asst. Professor, Department of Automobile Engineering, R. I. T. Sakharale, Maharashtra, India)
}

\begin{abstract}
India is a country where the main occupation is agriculture. More than $3 / 5^{\text {th }}$ of India's population is employed in this sector. Sugarcane is the largest crop cultivated in Indian farms. Bullock cart is the one of the two main transportation media used to transport sugarcane from agricultural land to the sugar factories. Bullocks used for this purpose suffer various problems. The main problem related with bullock cart is speed control. It is observed that to control speed of cart, cart riders do dangerous experiments like application of brake manually by directly putting wood in front of wheels, sitting backside of cart, applying tremendous force on bulls etc. Because of such unscientific methods major accident happens which causes major casualties. The purpose of present work is to provide scientific solution to control speed of cart.
\end{abstract}

Keywords: Bullock cart, Disc Brake, Braking Effort, Bulls Safety

\section{Introduction:}

It is often suggested that efforts should be focused on promoting mechanized, rather than animal-based, means of transport. However, the widespread use of motorized vehicles is dependent on the user's ability to find the necessary financial resources and on the existence of motorable roads and technical support services. Moreover, in many countries, the costs of importing oil are a limiting factor. Thus, while a steady growth in mechanization of transport is inevitable, animal-drawn transport can still play a significant role.

At present, the majority of people in developing countries are not adequately served by transportation systems. In rural areas, most people live at a considerable distance from a conventional road, and development of road network in rural area is a major issue. Road density will be reached in the coming future. Moreover, even in areas where settlements have access to roads, the economic conditions do not permit a large increase in the use of conventional motorized vehicles on an extended road network.

As India is developing country, majority of roads in villages are underdeveloped. Using motorized transport on such roads cause major problem of maintenance of vehicles. In some places it is not possible to reach with loaded vehicles. That's why for transportation of sugarcane major sugar factories and farmers use bullock cart. Animal-drawn pneumatic tyre carts are widely used in India because they are;

(a) Capable of meeting local transport needs efficiently

(b) Not restricted to use on motor able roads

(c) Affordable and socially acceptable

(d) Powered by renewable sources

(e) Suitable for production and maintenance using mainly local resources.

As per the current conditions, it is not possible to replace animal drawn carts but some improvements are possible to make transportation easy. About 15 million bullock carts exist in India as per animal welfare report. Maximum numbers of carts are used for transportation of sugarcane. These carts are pneumatic tyre carts. Statistic shows that number of bullock carts has not reduced in last 30 years, belying the popular concept that bullock carts will disappear with the development of society. Reasons are many. The fact is that still in India, bullock carts are the most important mode of transportation. Unfortunately, the technology of the carts has not been improved. As this mode of transportation will exist in India, there is need for the improvement of the technology. In this study effective braking system for pneumatic tyre carts used for transportation of sugarcane is designed developed and implemented. Also system is tested for loading.

\subsection{Speed of cart with load}

\section{Design Of Braking System For Pneumatic Tyre Cart:}

Before designing braking system, it is necessary to know the minimum, maximum and average speeds of the cart. For this measurement, following procedure is used:

- Make 15 checkpoints on the level road.

- The distance between two consecutive checkpoints is kept as 300 meter. 
- Note down time required for a cart (loaded with 2-3 ton weight) to cross these checkpoints.

- Take number of readings for different loaded carts.

- Calculate mean speed.

By using above procedure following table 4.1 is prepared and speed of cart is determined.

Table.2.1: Speed of Carts

\begin{tabular}{|c|c|}
\hline Cart No. & Average Speed of Cart (kmph) \\
\hline 1 & 5.56 \\
\hline 2 & 4.186 \\
\hline 3 & 4.268 \\
\hline 4 & 4.86 \\
\hline 5 & 5.22 \\
\hline 6 & 5.56 \\
\hline 7 & 4.621 \\
\hline 8 & 4.89 \\
\hline 9 & 5.02 \\
\hline 10 & 5.302 \\
\hline
\end{tabular}

Average speed of cart with load $=4.95 \mathrm{Kmph}$

\subsection{Brake Calculations:}

Brake Shoe Material - Asbestos, Armide

Required Data - Diameter of drum $=9$ inch $(225 \mathrm{~mm})(8.00-19)$ tyre

$\mathrm{R}=8$ inch

Shoe face width $=15$ inch

Force $=2220 \mathrm{~N}$

$\mu=0.28$ (Assumed)

Max load $=3$ tons

There are two shoes interacting with the brake drum. Each generates friction and applies torque to the drum, but one shoe will be self-energizing and the other will not be. This will be true regardless of the drum rotation direction, because of the symmetry of the geometry. The total torque on the drum will be the same regardless of drum rotation direction, so we are free to choose a clockwise rotation for the drum. For a clockwise rotation of the drum, the right shoe is self-energizing, because for the right shoe the friction force acting on the shoe causes a clockwise moment about its hinge pin, which is in the same direction as the applied force, F. In this way, the friction helps apply the brake; the other shoe will therefore not be self energizing.

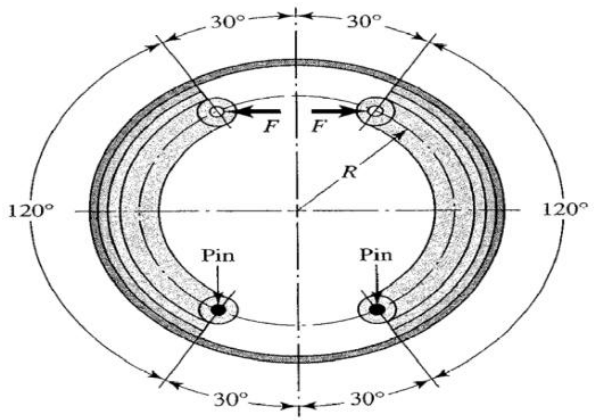

Fig. 2.1: Brake Shoe Diagram

(a) The moment of the friction force about the hinge pin, can be written as

(b) $\mathrm{M}_{\mathrm{f}}=\frac{\mathrm{fP}_{\mathrm{a}} \mathrm{br}}{\sin \theta \mathrm{a}} \int_{\theta 1}^{\theta 2} \sin \theta(\mathrm{r}-\mathrm{a} \cos \theta) \delta \theta$ (1)

The angles are $\theta_{1}=0^{\circ}$ and $\theta_{2}=120^{\circ}$

The angle at which the maximum pressure on the shoe occurs is

The distance $a$ is

$$
\varphi_{\mathrm{a}}=90^{\circ}
$$

The distance $c$ is

$$
a=\mathrm{R}=5 \text { in. }
$$


Therefore, the distance $c$ is

$$
c=2 R \cos 30^{\circ}
$$

$$
\begin{gathered}
c=2 \times 8 \times \cos 30^{\circ} \\
c=354.81 \mathrm{~mm} .
\end{gathered}
$$

Therefore, the moment of the friction force about the hinge pin is

$$
\mathrm{M}_{\mathrm{f}}=459.776 \mathrm{~mm}
$$

b) The moment of the normal force about the hinge pin is,

For the self-energizing (right) shoe,

$$
\begin{gathered}
\mathrm{M}_{\mathrm{N}}=\frac{\mathrm{P}_{\mathrm{a}} \text { bra }}{\sin \theta_{\mathrm{a}}}\left[\frac{1}{2}\left(\theta_{2}-\theta_{1}\right)-\frac{1}{4}\left(\sin 2 \theta_{2}-\sin 2 \theta_{1}\right)\right] \\
\mathrm{M}_{\mathrm{N}}=145587.2 \mathrm{~mm}
\end{gathered}
$$

The actuating force is specified to be

$$
\mathrm{F}=226.24 \mathrm{~kg} \text {. }
$$

Therefore the actuating force is

$$
\mathrm{F}=\frac{\mathrm{M}_{\mathrm{N}}-\mathrm{M}_{\mathrm{F}}}{\mathrm{C}}
$$

The maximum pressure at the self-energizing (right) shoe, is $\left(\mathrm{P}_{\mathrm{a}}\right)$ right $=178.12 \mathrm{psi}$. This is a reasonable pressure for sintered metal shoes, for which the maximum pressure is limited to 300 to 400 psi. Operated dry, their coefficient of friction is expected to be 0.29 to 0.33 .

c) Brake shoe calculations:-

The braking torque provided by the right shoe is

$$
\begin{aligned}
& \text { (T) })_{\text {Right }}=\frac{\mathrm{F}(\mathrm{Pa}) \text { rightb } \mathrm{r}^{2}\left(\cos \theta_{1}-\cos \theta_{2}\right)}{\sin \theta_{\mathrm{a}}} \\
& (\mathrm{T})_{\text {Right }}=\frac{0.28 \times 178.12 \times 1.5 \times 6^{2}(\cos 0-\cos 120)}{\sin 90} \\
& \text { (T) })_{\text {Right }}=4642.98 \mathrm{~mm}-\mathrm{kg}
\end{aligned}
$$

The left shoe is not self-energizing.

Therefore, for the left shoe, actuation force, is

$$
\mathrm{F}=\frac{M_{N}-M_{F}}{C}
$$

The actuation force on the left shoe is the same as on the right shoe $(226.26 \mathrm{~kg})$,

Therefore, the maximum pressure at the left shoe is

$$
\begin{gathered}
\mathrm{P}_{\text {left }}=\frac{500}{13.86} \\
\mathrm{P}_{\text {left }}=36.07 \mathrm{psi}
\end{gathered}
$$

Notice that the peak pressure on the left shoe (36.07 psi), the non-self-energizing one, is much lower than the pressure on the right self-energizing shoe (which was $178.12 \mathrm{psi}$ ). This is a direct result of the effects of the friction moment urging the right shoe into the drum, and urging the left shoe away from the drum.

The braking torque provided by the left shoe is

$$
\begin{aligned}
& \text { (T) })_{\text {Left }}=\frac{0.28 \times 36.07 \times 1.5 \times 6^{2}(\cos 0-\cos 120)}{\sin 90} \\
& \text { (T) })_{\text {Left }}=940.21 \mathrm{~mm}-\mathrm{kg}
\end{aligned}
$$

The braking torque provided by the left shoe is $36.07 \mathrm{psi}$

Therefore,

The total braking torque is,

$$
\begin{gathered}
T_{\text {total }}=4642.98+940.21 \\
=5583.20 \mathrm{~mm}-\mathrm{kg}
\end{gathered}
$$

Note that the self energizing right shoe generates almost double the torque of the left shoe, even though they have the same geometry, the same friction material, and are actuated with the same force. The difference is the right shoe has the friction moment urging the shoe into the drum, whereas the left shoe the friction moment urges the shoe away from the drum and reduces its lining pressure (c).

The components of the actuating force for the right shoe are,

The integrals A and B are,

$$
\left(R_{X}\right)_{\text {right }}=\frac{\left(P_{a}\right)_{\text {right }}}{\sin \theta_{a}}\left(A-F_{B}\right)-\left(F_{X}\right)_{\text {right }}
$$

$$
\begin{gathered}
A=\left[\frac{1}{2}(\sin 2120-\sin 20)\right] \\
\mathrm{A}=0.375 \\
=\frac{1}{2}\left(\frac{120 \times \pi}{180}-\frac{0 \times \pi}{180}\right)-\frac{1}{4}(\sin 240-\sin 0)
\end{gathered}
$$


The reaction forces of the shoe are,

$$
\mathrm{B}=1.264
$$

The magnitude of the net reaction force of the left shoe is,

$$
\begin{aligned}
R_{\text {right }} & =\sqrt{R_{X} 2+R_{Y}} 2 \\
& =\sqrt{-229^{2}+940^{2}} \\
& =30.31 \mathrm{~kg}
\end{aligned}
$$

$$
\begin{aligned}
\mathrm{R}_{\text {left }} & =\sqrt{130^{2}+171^{2}} \\
& =97.28 \mathrm{~kg}
\end{aligned}
$$

\subsection{Modeling of Drum brake.}

Pickup truck of Tata Motors, i.e. Tata 407 is having same axle size as that of carts used for sugarcane transportation. Tata 407 uses conventional drum brake mechanism. Both are also having same wheel size and load carrying capacity. Only difference in both vehicles is speed and acceleration. By considering that difference here, the calculation of braking system is done in above point. Modeling of different components of braking system is done in CATIA V5. Different components with assembly are as shown in following figures.

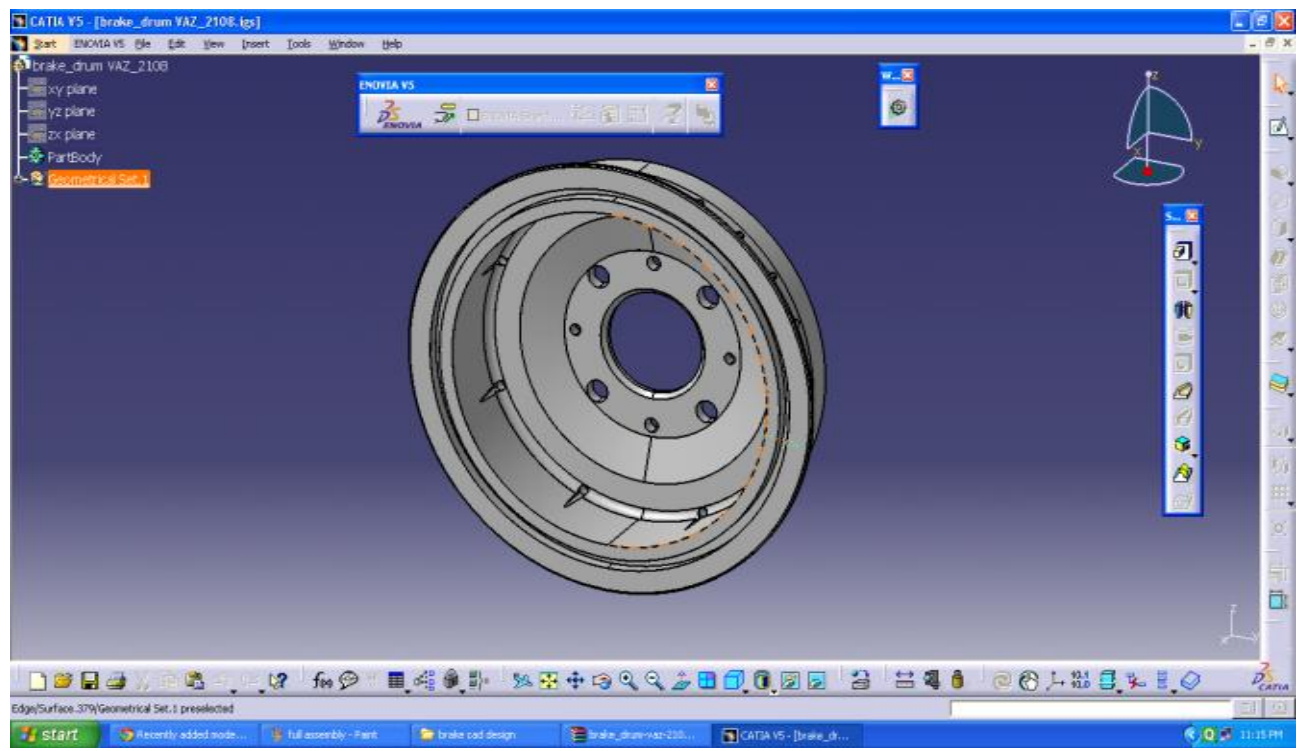

Fig. 2.2: Brake Drum

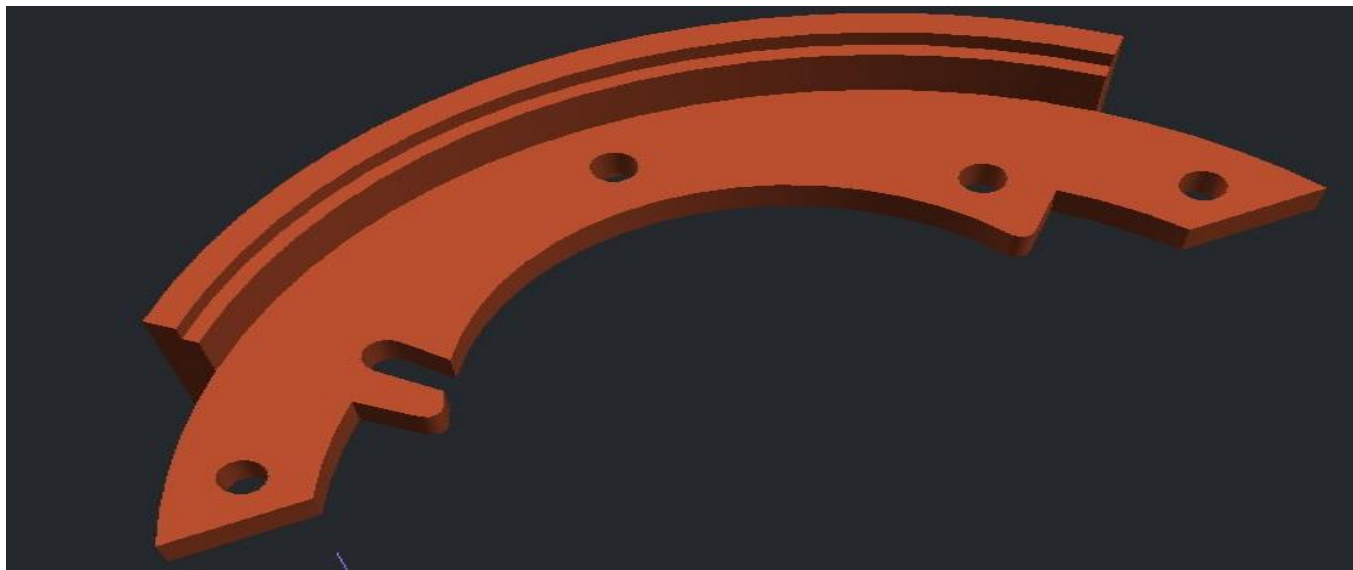

Fig. 2.3: Brake shoe 


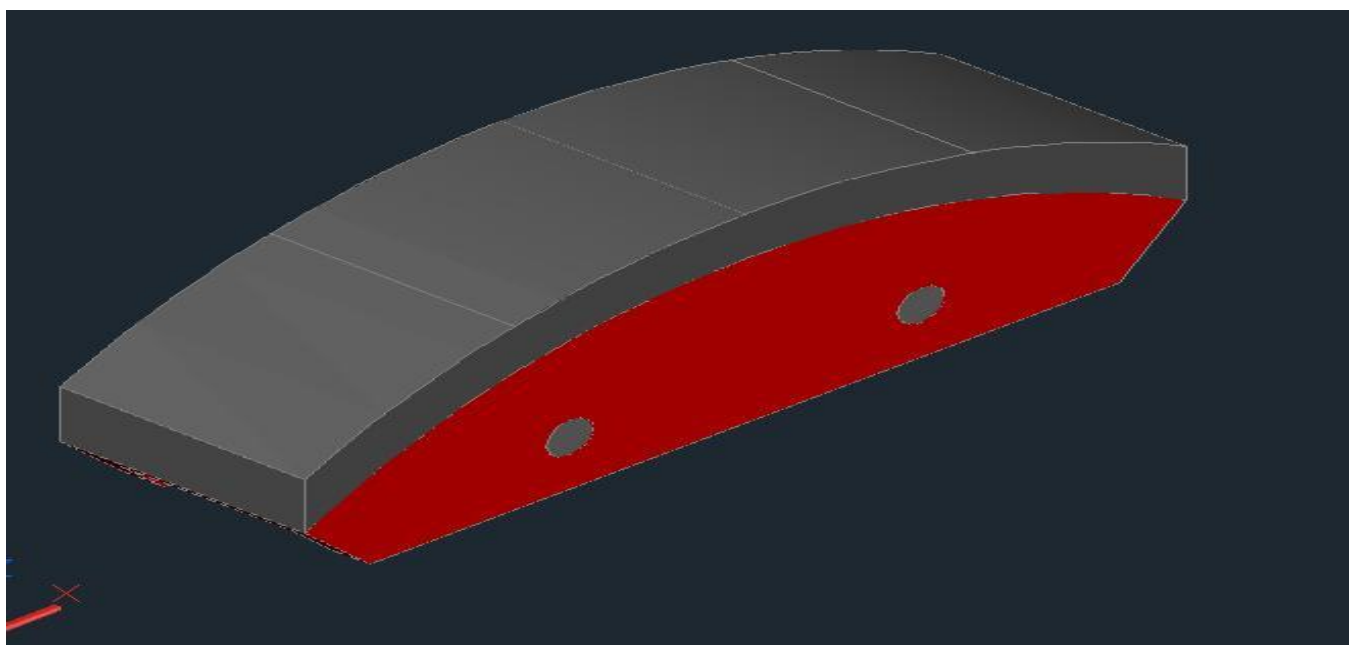

Fig. 2.4: Friction lining

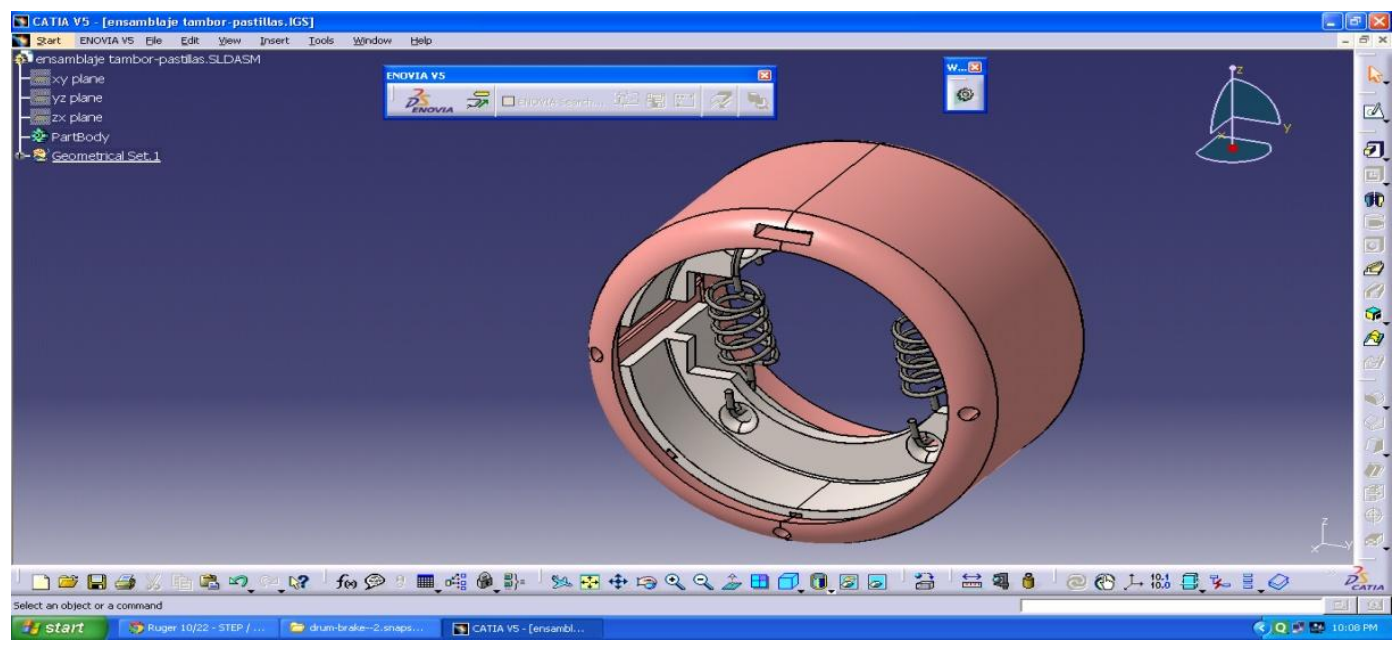

Fig. 2.5: Assembly of Brake

\subsection{Brake Implementation}

\section{System Implementation:}

Once all the braking system parts are manufactured, they implemented on cart axle. Following steps are followed for implementation of system:

i. Remove cart wheel using hydraulic jack.

ii. Remove original hub to implement new system hub.

iii. Fit hub cover after a little machining (diameter increment).

iv. Fit hub bearing on the axle.

v. Check fitting of hub on axle if fitting is improper then, does some machining on hub.

vi. Make assembly of brake shoes with the help of springs. Avoid direct contact of brake shoe with inner surface of the drum.

vii. Fit brake drum together with brake shoe on axle with the help of check nut. 


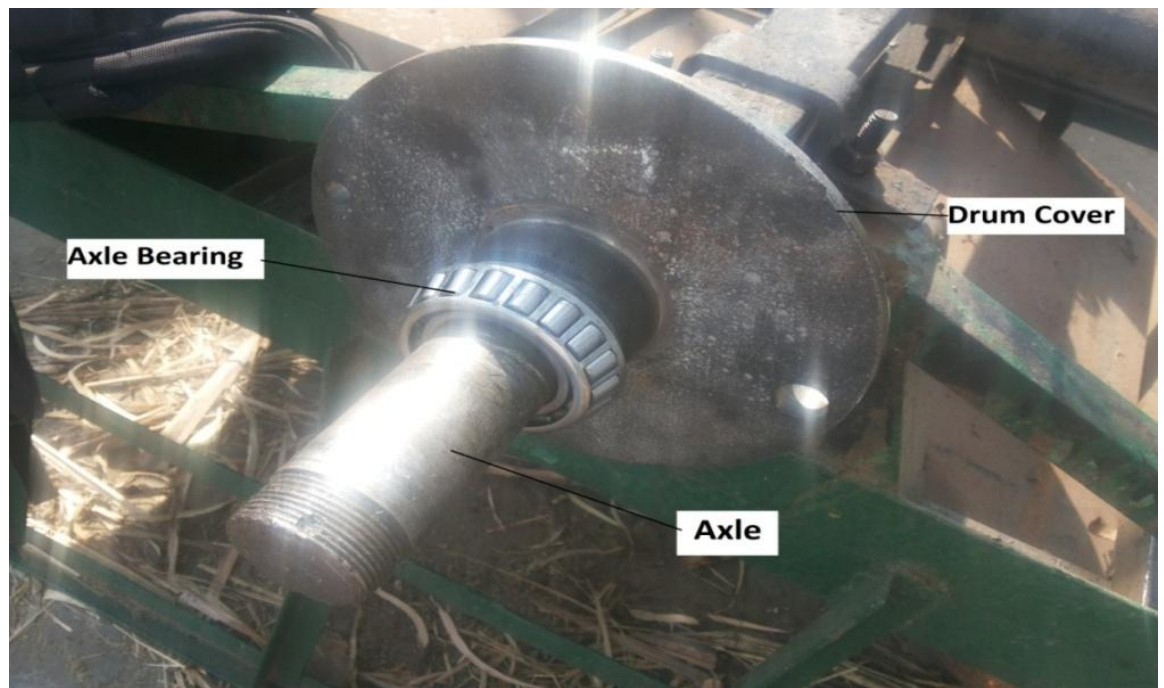

Fig. 3.1: Bearing Assembly

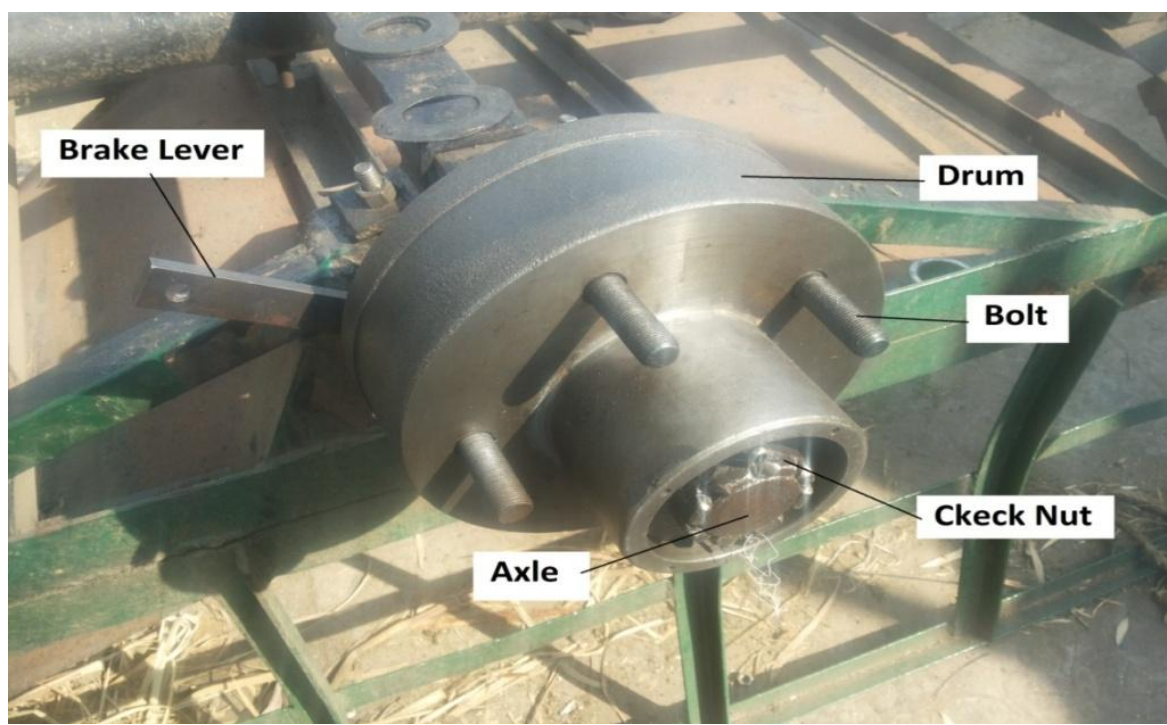

Fig. 3.2: Hub Assembly

\subsection{Linkage Implementation:-}

Linkage used for activating brakes consists of polished bar, brake lever, clutch wire, C clamp, plate with notches, and handle. The schematic diagram of operating mechanism is as shown in fig.

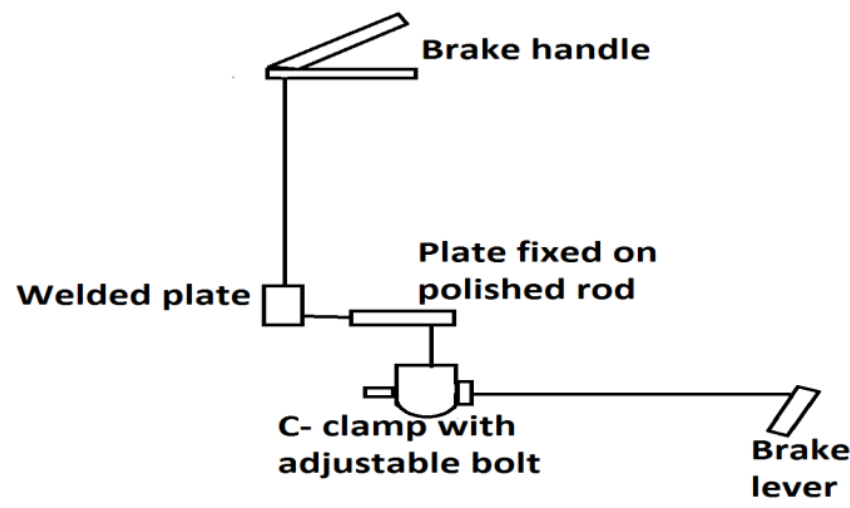

Fig. 3.3: Linkage mechanism 
The procedure for linkage implementation is as follows:

i) Weld $18 \mathrm{~mm}$ diameter and 42inch long steel polished rod with the front side of cart chassis.

ii) Weld C-clamp and notched plate to polished rod.

iii) Weld one more notched plate to cart body exactly above notched plate on polished bar.

iv) Make adjustable bolting arrangement of linkage bar coming from brake lever

v) Connect brake wire with notched plate on polished rod, pass it through notched welded plate welded to cart body and connect it to the hand operated lever.

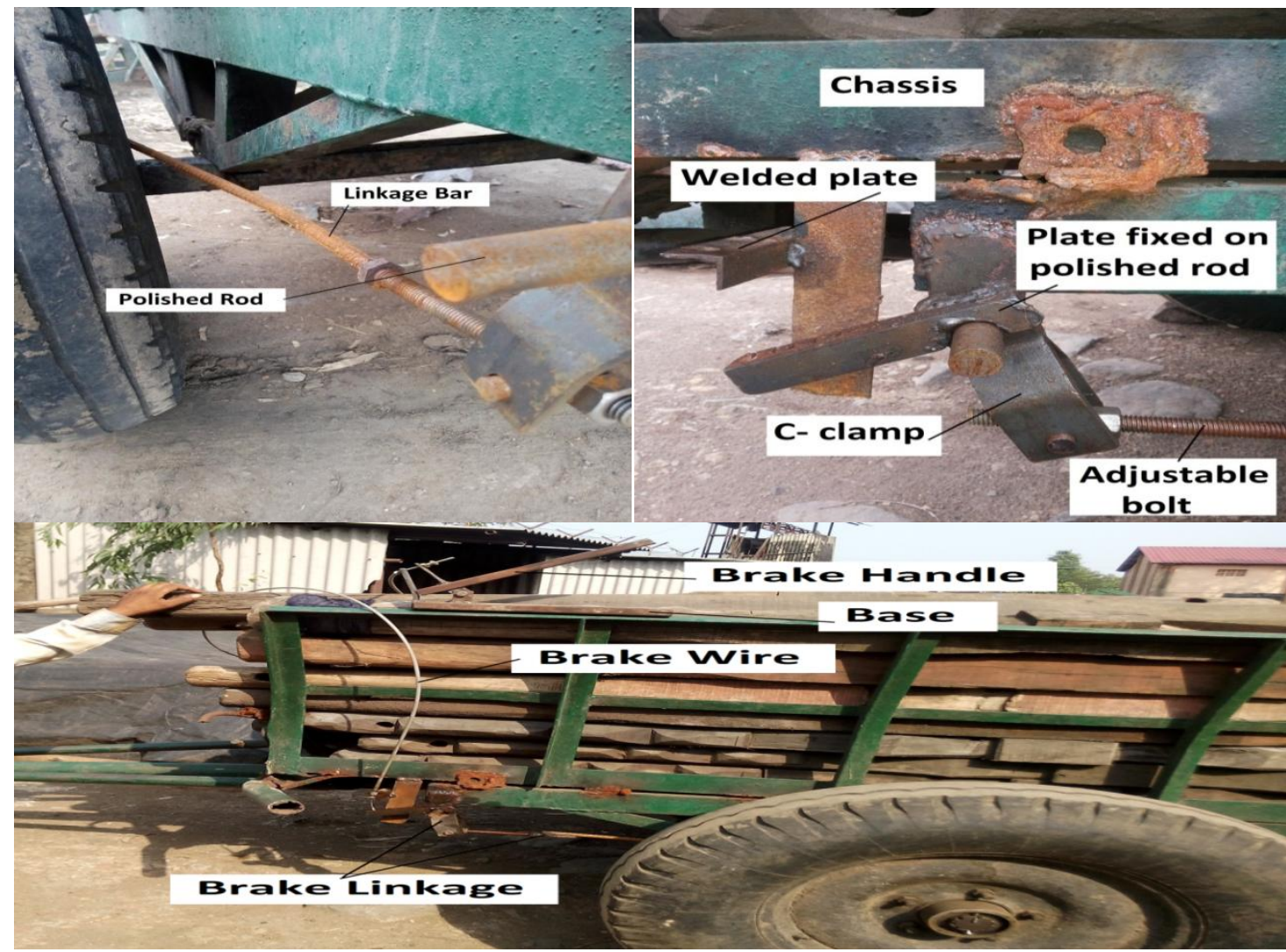

Fig. 3.4: Implementation of braking system on cart

\section{Result And Discussion}

An empty cart and loaded cart both are tested on flat road and on down hilling with and without application of braking system. Stopping distance and stopping time for both conditions is measured. The data is presented here in tabular format.

Table No. 4.1 Braking Effort when Cart is Empty (without brakes)

\begin{tabular}{|c|c|c|c|c|}
\hline \multirow{2}{*}{ Test No. } & \multicolumn{3}{|c|}{ Stopping Distance ( cm ) } & \multicolumn{2}{c|}{ Stopping Time ( sec ) } \\
\cline { 2 - 5 } & Flat Surface & Down Hill & Flat Surface & Down Hill \\
\hline 1 & 102 & 113 & 4.6 & 5.5 \\
\hline 2 & 96 & 115 & 4.4 & 5.3 \\
\hline 3 & 105 & 120 & 4.3 & 5.3 \\
\hline 4 & 98 & 115 & 4.8 & 5.1 \\
\hline 5 & 98 & 118 & 4.4 & 5.3 \\
\hline
\end{tabular}

Table No. 4.2 Braking Effort when Cart is loaded (without brakes)

\begin{tabular}{|c|c|c|c|c|}
\hline \multirow{2}{*}{ Test No. } & \multicolumn{2}{|c|}{ Stopping Distance ( cm ) } & \multicolumn{2}{c|}{ Stopping Time ( sec ) } \\
\cline { 2 - 5 } & Flat Surface & Down Hill & Flat Surface & Down Hill \\
\hline 1 & 81 & 93 & 4.6 & 4.9 \\
\hline 2 & 80 & 91 & 4.2 & 5.0 \\
\hline 3 & 77 & 94 & 4.1 & 4.8 \\
\hline 4 & 85 & 98 & 4.3 & 4.7 \\
\hline 5 & 82 & 95 & 4.0 & 5.0 \\
\hline
\end{tabular}


Table No. 4.3 Braking Effort when Cart is Empty (with brakes)

\begin{tabular}{|c|c|c|c|c|}
\hline \multirow{2}{*}{ Test No. } & \multicolumn{2}{|c|}{ Stopping Distance ( cm ) } & \multicolumn{2}{c|}{ Stopping Time ( sec ) } \\
\cline { 2 - 5 } & Flat Surface & Down Hill & Flat Surface & Down Hill \\
\hline 1 & 72 & 83 & 2.6 & 3.1 \\
\hline 2 & 69 & 88 & 2.5 & 3.2 \\
\hline 3 & 73 & 90 & 2.5 & 3.3 \\
\hline 4 & 69 & 85 & 2.5 & 3.1 \\
\hline 5 & 65 & 88 & 2.4 & 3.3 \\
\hline
\end{tabular}

Table No. 4.4 Braking Effort when Cart is loaded (with brakes)

\begin{tabular}{|c|c|c|c|c|}
\hline \multirow{2}{*}{ Test No. } & \multicolumn{2}{|c|}{ Stopping Distance ( cm ) } & \multicolumn{2}{c|}{ Stopping Time ( sec ) } \\
\cline { 2 - 5 } & Flat Surface & Down Hill & Flat Surface & Down Hill \\
\hline 1 & 54 & 66 & 2.1 & 2.9 \\
\hline 2 & 48 & 66 & 2.2 & 3.0 \\
\hline 3 & 51 & 69 & 2.1 & 2.8 \\
\hline 4 & 46 & 65 & 2.3 & 2.6 \\
\hline 5 & 48 & 68 & & 2.5 \\
\hline
\end{tabular}

\subsection{Discussion of test results}

Test records obtained under various operating conditions for carts fitted with pneumatic wheels is analyzed as below.

1. Stopping distance and time of empty cart on flat road is less as compared to same on the downhill.

2. Stopping distance and time of loaded cart on flat road is less as compared to same on the downhill.

3. Efforts required to stop loaded cart is much more on downhill. It is also dangerous for human life. It demands a lot of force on bulls.

4. When braking system is applied then there is improvement in stopping distance and stopping time.

5. During downhill job becomes very easy even single operator is able to control speed of cart with less efforts.

\section{Comparison for braking efforts, with and without braking system}

1. When there is provision of braking system, the stopping distance of cart on the flat road is about $30 \%$ less as compared to the cart without braking system.

2. Also the stopping time is saved by nearly $50 \%$ on the flat road when braking system is used.

\section{Conclusion}

This solution provided by 'Bullock Friendly Cart' will give economic solution to bullock cart problem. Various sugarcane factories need to take initiative for this 'Bullock Friendly cart'. Braking system implementation on bullock carts makes sugarcane transportation safer. It also provides some kind of relief to bulls during downhill and uphill. Even single operator is able to control loaded cart on any kind of surface. The study of 'Bullock Friendly Cart' leads to understand the various solutions which will help in minimizing the efforts of bulls. Braking system implemented on the cart will help the bulls to avoid dangers in down hilling and accidental situations.

System results indicate that human life will become safer because it stops the cart as per operators will. It also helps bullocks to get comfort because stopping of cart on downhill was major issue which is solved by this system.

\section{References}

[1]. A. A. Herbart and A. O. Currie, Axle Carrier Manufacturing and implementing, Borg Warner Australia, Pontiac firebird, 25-29, (2006).

[2]. L. Kapelevich, Y. V. Shekhtman, 'Direct Gear Design: Bending Stress Minimization', Gear Technology, September/October, 44 49, (2003).

[3]. J. Plumbe and D. J. Savage, 'Bullock cart haulage in Sri Lanka. Department of the Environment Department of Transport TRRL Laboratory Report LR1OO6. Crowthorne, Transport and Road Research Laboratory. (1981).

[4]. M R Raghavan, D L Prasanna Rao, 'A study on bullock carts', Department of Mechanical Engineering, Indian Institute of Science, Bangalore 560 012, (1979).

[5]. Raghavan, M. R. and H. R. Nagendra, 'Engineering analysis of the two wheeled bullock cart design', C2, Part 4, December, (1979).

[6]. S. S. Venkatramanan, 'Value Engineering The Ox Cart- A Project Toward The Goal of World Happiness' CVS Venconvave Private Limited, C 50, N.D.S.E. - I, (1995).

[7]. K. N. Ramanujam, 'Rural Transport in India', first Edition, p.p. 45-90, (1993).

[8]. Santosh S Bagewadi and Dr. S. N. Kurbet, 'Spiral Bevel Pinion for Mahindra Bolero Gearbox', (2012). 